\title{
INFORMAÇÕES E PRÁTICAS DA CONTABILIDADE GERENCIAL UTILIZADAS POR MICRO E PEQUENAS EMPRESAS
}

Rodrigo Menegon ${ }^{1}$

Claudia Dalla Porta ${ }^{1}$

Silvana Dalmutt Kruger ${ }^{1}$

Antonio Zanin ${ }^{1}$

${ }^{1}$ Universidade Comunitária da Região de Chapecó 


\title{
INFORMAÇÕES E PRÁTICAS DA CONTABILIDADE GERENCIAL UTILIZADAS POR MICRO E PEQUENAS EMPRESAS
}

\begin{abstract}
Resumo
O objetivo do estudo é identificar o estágio evolutivo da contabilidade gerencial das micro e pequenas empresas do município de Chapecó/SC. A pesquisa utiliza o questionário de AbdelKader e Luther (2008), para coleta das informações da amostra de 27 empresas. Os resultados apontam que 05 empresas possuem características do estágio 1; 09 no estágio 2, onde utilizam de gestão planejada baseada em análises de dados; 11 empresas no estágio 3 com características voltadas para a redução dos desperdícios de recursos e do uso de tecnologias na melhoria de processos; e 02 empresas no estágio 4, que inclusive, observou-se a idade e o faturamento maior em relação as demais como diferencial do uso de instrumentos de gestão caracterizados modernos. O estudo contribui para evidenciar as características predominantes das empresas quanto ao uso de práticas e instrumentos da contabilidade gerencial, vinculados ramo de atividade, faturamento e número de funcionários.
\end{abstract}

Palavras-chave: Contabilidade Gerencial. Micro e Pequenas Empresas.

\section{Introdução}

O atual ambiente dos negócios exige das empresas estratégias voltadas ao gerenciamento das informações e ao uso de recursos inteligentes. O uso de sistemas de controle gerencial auxilia no planejamento, organização e controle das empresas, gerando informações em tempo hábil para o processo de tomada de decisão (Bazzotti \& Garcia, 2006; Beuren \& Oro, 2014).

Toda empresa, independente do porte ou ramo de atividade, utiliza-se de estratégias para alcançar seus objetivos e se manter competitiva. O planejamento estratégico é uma das ferramentas para executar a gestão empresarial, que tem como objetivo auxiliar nas tomadas de decisões frente ao ambiente interno e externo. O uso de estratégias é essencial para que a empresa tenha visão crítica do futuro, analisando seu campo de atuação sob a perspectiva dos seus clientes e concorrentes e buscando o lucro desejado (Fernandes, 2004; Nisiyama \& Oyadomari, 2012).

As micro e pequenas empresas convivem com muitas incertezas em seus primeiros anos de existência, e isso tem muita relação com a competência dos proprietários, colaboradores e ao fator de restrição de financiamentos. Entre os principais problemas que ocasionam o fechamento das micro e pequenas empresas estão a falta de capital de giro, a carga tributária elevada, os problemas financeiros, a concorrência e a recessão econômica no país (Da Costa Ferreira, Da Silva Macedo, De Sant'Anna, Longo, \& Barone, 2011).

Os principais motivos que levam as micro e pequenas empresas a fecharem, segundo Ghilardi (2011), é a falta de planejamento e conhecimento sobre o mercado de atuação em geral, sem 
um planejamento prévio sobre o ramo do negócio, além da limitação de recursos financeiros, falta de conhecimento sobre os custo dos produtos, entre outros.

Perufo e Godoy (2019), também evidenciam que o principal causa para a mortalidade precoce das microempresas é a falta de planejamento estratégico, enquanto que os principais fatores relacionados ao encerramento das atividades, estão relacionados ao baixo nível de inovação, centralização do poder, confusão com as finanças entre pessoas física e jurídica e a dificuldade de conseguir acesso a crédito por instituições financeiras.

Em contraponto, a falta de informações, ao longo das últimas décadas a contabilidade e o uso dos sistemas de controle gerencial (SCG), com foco para a inovação, têm se tornado instrumentos de apoio a gestão e ao planejamento estratégico (Utzig \& Beuren, 2014). Os SCGs reúnem práticas de contabilidade gerencial, fornecendo informações sobre custos e orçamentos, possibilitando a análise criteriosa dos resultados e a construção de metas para a gestão do negócio. O controle gerencial é composto por procedimentos usados na gestão e informações da rotina da organização, e tem por finalidade dar o suporte necessário para o planejamento, alinhamento dos objetivos, ações corretivas, e para os feedbacks na organização (Beuren \& Oro, 2014).

A estrutura organizacional das empresas pode ser percebida pelos controles e pelo uso das informações. O controle gerencial serve para monitorar os resultados econômicos e financeiros que a empresa espera, obtido pela aplicação dos recursos, mitigando os riscos e ameaças e fomentando oportunidades que há no processo decisório de uma gestão (Heinzmann \& Lavarda, 2011).

A Internacional Federation of Accountants (IFAC, 1998), apresentou as especificidades desenvolvidas pela contabilidade gerencial ao longo dos anos, considerados como estágios evolutivos a maneira de gerenciar os recursos. O primeiro com foco nos custos e controle financeiro, o segundo relacionado ao uso das informações para o planejamento e controle gerencial; o terceiro estágio já observa a redução de desperdícios de recursos com o auxílio da tecnologia para análises de processos; e o quarto e último estágio tem foco na criação de valor por meio dos recursos e do uso de tecnologias e informações mais avançadas (Campos, Marques, \& Neto, 2019).

Destarte, formulou-se o problema do presente estudo: Quais as características da estrutura da contabilidade gerencial das micro e pequenas empresas do município de Chapecó-SC? O objetivo da pesquisa é identificar o estágio evolutivo da contabilidade gerencial a partir das práticas e informações utilizadas pelas micro e pequenas empresas do município de Chapecó/SC

Justifica-se a relevância da pesquisa, ponderando-se a importância de conhecer as características das empresas e como elas atuam em seus processos de decisão e no uso da informação da contabilidade gerencial para conduzir seus negócios, observando-se que a utilização de práticas gerenciais, de controle e planejamento e da análise das informações pode-se reduzir as fragilidades do processo de gestão empresarial.

\section{Referencial Teórico}

Nesta seção apresenta-se o contexto dos sistemas de controle gerencial e os aspectos relacionados ao ciclo de vida das organizações, bem como estudos correlatos. 


\subsection{Sistemas de controle gerencial}

Os sistemas de controle gerencial são processos no qual o gerente executa de forma eficaz para alcançar um determinado objetivo estabelecido. Ele é representado por um conjunto de subsistemas integrados, capaz de gerar e oferecer informações que levam os gestores à tomada de decisão. Seu propósito é ajudar a alcançar os objetivos da empresa oferecendo informações detalhadas e que os gestores possam utilizá-las com efetividade nas tomadas de decisões corporativas (Bazzotti \& Garcia, 2006).

Seu conceito vem evoluindo, o que antes era uma prestação de informações financeiras, tornou-se uma ferramenta que auxilia na tomada de decisões gerenciais que contempla outros tipos de informações relacionadas aos clientes, mercados, concorrentes, informações não financeiras entre outras. Isso faz com que o SCG contribua na orientação da inovação, pois há um número maior de informações disponíveis aos administradores e com isso tomem decisões mais assertivas (Beuren \& Oro, 2014).

O controle gerencial teve ênfase em 1950, quando começaram surgir estudos mais aprofundados sobre o assunto, sofrendo uma expansão conceitual, e que após alguns anos começou a incorporar outras ciências como a sociologia e psicologia, onde as pesquisas sobre o assunto tiveram mudanças significativas (Gomes, 1997). Atualmente os sistemas de controle gerencial estão baseados em planejamentos, medição de desempenho, acompanhamento de atividades, inovação para o processo de comportamento organizacional, entre outros (Dallabona, Nardelli, \& Fernandes, 2019).

Para Anthony e Govindarajan (2008), o controle gerencial tem por finalidade assegurar o cumprimento das estratégias de forma que sejam atingidos os objetivos da organização. As principais atividades incluem o planejamento sobre o que deve ser realizado, coordenação geral de todas as atividades internas, comunicação de informação, decisões a serem tomadas mediante as escolhas e influências sobre as pessoas no intuito de mudar seu comportamento.

No controle gerencial as ações não precisam corresponder ao plano determinadamente previsto, pois no momento de sua aplicação, a realidade pode ter mudado desde o momento que foi planejado. Com isso, no instante da implantação, os objetivos anteriores podem ser aprimorados com os objetivos atualmente necessários (Anthony \& Govindarajan, 2008). Para Dos Santos, Beuren, Corrêa, \& Martins (2018), a contabilidade gerencial é um mecanismo que auxilia a empresa a sobreviver em meio a concorrência.

Para controles gerenciais mais modernos, encontra-se a combinação de informações financeiras e não financeiras, juntas em uma estratégia, e são consideradas práticas capazes de relacionar operações e atividades estratégicas. Ou seja, na concepção do custeio baseado em atividade, dos sistemas que medem o desempenho contemporâneo e também nas técnicas de benchmarking. Já os instrumentos tradicionais estão relacionados aos sistemas de orçamento, avaliação e mensuração de desempenho, relatórios departamentais, controle a análise da relação custo-volume-lucro. Desenvolvidos antes da década de 1980 os controles gerenciais tradicionais se classificam em: custeio variável, por absorção, custo padrão e retorno por investimentos (Dos Santos et al., 2018). 


\subsection{Artefatos e Estágios Evolutivos da Contabilidade Gerencial}

A contabilidade gerencial, bem como as outras áreas ligadas a ela, apresentam uma evolução, onde o seu foco e objetivo vão mudando, refletindo no processo de planejamento e na tomada de decisões dentro das empresas (Soutes \& De Zen, 2005). Com isso, o International Federation of Accountants (IFAC), por meio do documento International Managemente Accounting Practice 1 (IMAP 1), identificou quatro etapas evolutivas da contabilidade gerencial no intuito de linear a área de atividade das empresas, conforme o passar dos anos. Cada estágio representa uma fase estruturada de um novo conjunto de condições em que as empresas se encontram, enfrentando, reformando e absorvendo as tecnologias de cada estágio e dos estágios anteriores (Isidoro, Facci, Espejo, Garcias, \& Moller, 2011).

No primeiro estágio (antes de 1950) estão as características mais técnicas, voltadas aos custos e controle financeiro, onde as empresas usavam as tecnologias para identificar com facilidade os custos de mão de obra e de matéria-prima. Essa era a principal ferramenta gerencial utilizada pelos administradores das empresas. Devido aos produtos serem bem vendidos e o processo de produção bem compreendido, ocorria que não havia ideias inovadoras para melhoria dos produtos e processos, afetando o gerenciamento (Mattos, Da Costa Freitag \& Junior, 2010). Durante esse estágio o que influenciava o processo era a velocidade de operações feitas manualmente, o que gerava uma base em cima disso para os gastos indiretos do produto (Grande \& Beuren, 2011).

No segundo estágio, entre os anos de 1950 a 1965, os gestores voltaram-se para práticas que possibilitassem um aprimoramento nas informações de controle e planejamento, comparado pelo IFAC como uma assessoria interna, onde a contabilidade gerencial, por meio das análises e escolhas gerenciavam a organização. O maior objetivo dos gestores neste estágio era de que os recursos fossem utilizados da melhor forma para o alcance do objetivo da empresa. (Mattos, Da Costa Freitag \& Junior, 2010; Isidoro et al., 2011).

A redução do desperdício de recurso foi marcada no terceiro estágio, onde entre os anos de 1970 e 1980, ocorreu um recesso e em seguida da alta do valor do petróleo da competição global, ameaçou os mercados estabelecidos no Ocidente. Isso ocasionou um rápido desenvolvimento tecnológico que instigou mudanças em aspectos do setor industrial. Com o uso da inovação e da robótica os custos foram sendo reduzidos, criando novas técnicas de gerenciamento e produção e aumentando o controle dos custos, por meio da redução de desperdício de recursos que eram utilizados no processo de negócios (Mattos, Da Costa Freitag \& Junior, 2010). A gestão baseia-se em valores, centro de responsabilidade, valor da transferência, método de custo kaisen, custeio meta entre outros (Teixeira, Gonzaga, Santos \& Nossa, 2011).

O estágio quatro, a partir do ano de 1990, foi marcado pelo desenvolvimento tecnológico e de processamento de informações. Com o uso da rede mundial de computadores surgiu o comércio eletrônico e impulsionou a competitividade global, o foco então era o de criar valor por meio do uso eficaz de recursos (Mattos, Da Costa Freitag \& Junior, 2010). Seu foco central é criar valor através de recursos que a tecnologia oferece, direcionados aos clientes e acionistas e a inovação organizacional (Campos, Marques, \& Neto, 2019).

Quando os estágios foram diagnosticados, o processo de um para o outro era em forma de evolução e adaptação, embora não se anula o anterior para a criação de outro. Cada estágio é a 
combinação do anterior e do atual em direção a novas condições no ambiente gerencial de uma empresa (IFAC, 1998).

Juntamente com os estágios, há também a evolução dos artefatos de contabilidade gerencial. Apesar de haver um enquadramento de artefatos com cada estágio, isso não quer dizer que somente sejam utilizados nos estágios em que estão classificados, podendo os mesmos estarem nos demais estágios evolutivos. Por essas etapas serem evolutivas, não há um encerramento de um estágio para o outro iniciar, mas sim um crescente aperfeiçoamento dos artefatos utilizados e da ideologia de cada estágio (Soutes \& De Zen, 2005).

O Quadro 1 apresenta a classificação em estágios evolutivos da contabilidade gerencial propostos e os instrumentos ou práticas da contabilidade gerencial em cada estágio.

Quadro 1: Estágios evolutivos, posição da contabilidade gerencial e práticas de controladoria

\begin{tabular}{|l|l|l|l|l|}
\hline Estágio & Período & $\begin{array}{l}\text { Foco de atuação da contabilidade } \\
\text { gerencial }\end{array}$ & Instrumentos/práticas \\
\hline Estágio 1 & $\begin{array}{l}\text { Antes de } \\
1950\end{array}$ & $\begin{array}{l}\text { Foco na determinação de custos e } \\
\text { controle financeiro, através do uso de } \\
\text { orçamentos e tecnologias de } \\
\text { contabilidade de custos. }\end{array}$ & $\begin{array}{l}\text { Análise do retorno sobre investimentos } \\
\text { (ROI), Custeio absorção, custeio direto, } \\
\text { custeio padrão e custeio variável. }\end{array}$ \\
\hline Estágio 2 & $\begin{array}{l}\text { De 1950 a } \\
1965\end{array}$ & $\begin{array}{l}\text { Foco no fornecimento de informações } \\
\text { para planejamento e controle gerencial, } \\
\text { através do uso de tecnologias, tais como } \\
\text { análise de decisão e contabilidade por } \\
\text { responsabilidade. }\end{array}$ & $\begin{array}{l}\text { Análise custo/volume/lucro; Análise do } \\
\text { valor presente (VPL), Avaliação de } \\
\text { desempenho, Preço de transferência, } \\
\text { Orçamento. }\end{array}$ \\
\hline Estágio 3 & $\begin{array}{l}\text { De 1965 a } \\
1985\end{array}$ & $\begin{array}{l}\text { Atenção na redução de desperdício dos } \\
\text { recursos utilizados nos processos da } \\
\text { empresa, através do uso da análise de } \\
\text { processos e tecnologias de } \\
\text { gerenciamento de custos. }\end{array}$ & $\begin{array}{l}\text { Custeio por atividades (ABC), Custeio } \\
\text { Kaisen, Custeio meta. Indicadores de } \\
\text { desempenho. }\end{array}$ \\
\hline Estágio 4 & $\begin{array}{l}\text { De 1985 } \\
\text { até hoje }\end{array}$ & $\begin{array}{l}\text { Atenção na geração de valor através do } \\
\text { uso efetivo de recursos, de tecnologias } \\
\text { que examinam os direcionadores de valor } \\
\text { para o cliente e para o acionista, e de } \\
\text { inovação organizacional. }\end{array}$ & $\begin{array}{l}\text { Balanced Scorecard (BSC), Gestão } \\
\text { baseada em Valor, Indicadores Chave de } \\
\text { Desempenho (KPI), Sistema de Gestão } \\
\text { Econômica } \\
\text { (GECON), Teoria das } \\
\text { Restrições, Valor econômico adicionado } \\
\text { (EVA), Planejamento } \\
\text { Estratégico, } \\
\text { Métodos de Avaliação de Desempenho }\end{array}$ \\
\hline
\end{tabular}

Fonte: Soutes (2006); Abdel-Kader e Luther (2008); Isidoro et al. (2011).

Dentre os artefatos, se encontram no primeiro estágio chamado de "Determinação dos custos e controle financeiro": Custeio por Absorção, Custeio Variável, Controle Financeiro e Operacional e Orçamento Anual. O segundo estágio, chamado "Informação para planejamento e controle gerencial”, estão os artefatos de: Custo Padrão, Custo Baseado em Atividades, Método de Custeamento RKW, Orçamento de capital e Descentralização. Já o terceiro estágio denominado "Redução de perdas de recursos em processos organizacionais" encontram-se: Gestão Baseada em Atividades, Centros de Responsabilidade, Preço de Transferência, Custo Meta, Método de Custeio Kaizen e Custeio do Ciclo de Vida. O quarto e último estágio evolutivo, denominado "Criação de valor através do uso efetivo dos recursos" possui no seu enquadramento os artefatos: Planejamento Estratégico, Balanced ScoreCard e Método de Avaliação de Desempenho (Soutes \& De Zen, 2005; Isidoro et al., 2011). 
As micro e pequenas empresas possuem características próprias de gestão e competitividade, com especificidades organizacionais, decisionais e individuais, segundo Leone (1999). Especificidades como, gestão centralizada, estrutura e sistemas de informação simples, pobreza de recursos, tomada de decisão intuitiva, alto grau de autonomia nas decisões, influência pessoal do proprietário e falta de separação dos gastos pessoais com o do negócio, propriedade do capital etc. interferem no desempenho e continuidade dessas organizações (Cezarino \& Campomar, 2006)

A inovação também precisa fazer parte dos negócios, acelerando o seu crescimento em relação à concorrência, adquirindo boas práticas e atraindo novos fundos de investimentos. Porém, as micro e pequenas empresas têm dificuldade maior para praticar a inovação (De Vicente Bittar, Di Serio \& De Vasconcellos, 2018). Porém essas empresas disputam espaços com as grandes empresas mesmo que elas apresentem maior capacidade financeira e estratégias mais abrangentes em desenvolver inovações (Silva \& Dacorso, 2013). Os recursos financeiros de uma empresa influenciam o seu crescimento e isso ocorre o inverso quando seus recursos forem escassos (Penrose \& Penrose, 2009).

Mahamid (2012), identificou cinco fatores potencializadores para a falência das MPEs, que são eles: a falta de gestão de seus clientes, baixo poder de competitividade das MPEs, instabilidade nos custos de material para fabricação ou prestação de serviços, falta de organização em relação aos descontos concedidos e, por fim, a limitação de crédito para suprir e manter as atividades empresariais.

\subsection{Estudos assemelhados}

Estudos anteriores evidenciam a análise dos estágios evolutivos da contabilidade gerencial nas empresas, ponderando sobre o ramo de atividade, região de atuação e o uso dos artefatos da contabilidade gerencial.

Macohon e Beuren (2016) realizaram um estudo sobre quais eram os estágios evolutivos da contabilidade gerencial que predominavam em indústrias moveleiras. Com uma amostra, não probabilística, de 15 indústrias, onde encontraram que 58\% dos artefatos implantados estão caracterizados como Estágio 1. O estágio 2 vem logo em seguida com 53\%. Os estágios 3 e 4 ficaram com $40 \%$ e $21 \%$ respectivamente dentre os artefatos que são utilizados ou pretendem ser utilizados pelas empresas do setor moveleiro da cidade de São Bento do Sul/SC.

Soutes e De Zen (2005) buscaram identificar o estágio evolutivo da contabilidade gerencial em que as empresas brasileiras se encontram por meio de quais artefatos as mesmas estão utilizando. Por meio de questionário aplicado a profissionais, estudantes de pós-graduação, onde levantou-se os benefícios e o uso nas empresas brasileiras, percebidos por eles, bem como fatores que restringem ou aceleram sua utilização. Indicam que os três primeiros estágios têm predominância na contabilidade gerencial, nessas empresas, porém indicam que há muito espaço para a evolução e desenvolvimento com o uso de artefatos mais modernos.

Isidoro et al. (2011) buscaram identificar os artefatos gerenciais que as cooperativas utilizam e se isso impacta no resultado delas. A amostra foi retirada da Revista Exame - Melhores e Maiores de 2010, filtrando as somente para cooperativas de agronegócio, onde aplicaram um questionário obtendo um retorno de 13 questionários respondidos. Com a análise desses dados identificaram que poucas cooperativas já se encontram no quarto estágio, e que o desempenho 
não está ligado ao uso de artefatos mais modernos (quarto estágio) e que o desempenho melhora nas empresas que encontram-se no terceiro estágio.

Abdel-Kader e Luther (2008), buscaram explicar porque as empresas adotam práticas de contabilidade gerencial, baseando-se na teoria da contingência. Foram escolhidas empresas holandesas de gás e energia, analisando características do ambiente interno e externo das empresas, suas estratégias, tamanho e processos de produção. Foram encontradas diferenças no estágios de controle gerencial e sofisticação das práticas de contabilidade, explicadas pela incerteza ambiental, poder do cliente, tamanho e descentralização.

Reis e Teixeira (2013) verificaram em suas pesquisas o uso de artefatos de contabilidade gerencial (tradicional ou moderno) em cooperativas agroindustriais de minas gerais e relacionar com o desempenho financeiro das mesmas. Os autores dividiram os estágios evolutivos da contabilidade gerencial em tradicionais (estágio 1 e 2) e modernos (estágio 3 e 4). Após analisarem os dados encontrados, constatam que não há diferença no desempenho financeiro das cooperativas que utilizam dos artefatos tanto tradicionais quanto modernos, ou seja independente de qual estágio evolutivo estejam classificados.

Os resultados destacam que de forma geral que o uso de informações da contabilidade gerencial ocorre nas organizações independente do ramo ou porte, porém quando observado por meio dos estágios evolutivos ocorre distinção dos instrumentos de apoio a gestão, observando-se que as empresas fazem uso de instrumentos tradicionais e modernos.

\section{Procedimentos Metodológicos}

Essa pesquisa, de natureza teórica e empírica, baseou-se no conceito de sistemas de controle com foco na contabilidade gerencial. Quanto aos objetivos se caracteriza como uma pesquisa descritiva, a fim de esclarecer determinadas características do estudo, com abordagem qualitativa, visto que se pretende conhecer a natureza de um determinado fenômeno, quanto aos procedimentos, enquadra-se como survey, pelos dados serem coletados com base em uma amostra que se deseja conhecer (Raupp \& Beuren, 2006).

Como método da coleta de dados se utilizou de questionário baseado no estudo de AbdelKader e Luther (2008), a respeito do impacto das características da empresa em práticas de contabilidade gerencial, no Reino Unido, tendo em vista a relevância do assunto abordado pelos autores e a relevância na região objeto deste estudo.

O grupo amostral é composto por 94 micro e pequenas empresas localizadas na cidade de Chapecó-SC, clientes de uma instituição financeira de nível nacional, com agências no lócus do estudo. O questionário foi enviado para 94 empresários via correio eletrônico, destes, foram recebidas efetivamente 27 respostas válidas e qualificadas, conforme o objetivo do estudo, perfazendo uma amostra percentual de 28,72\%. As empresas participantes deste estudo atuam, em sua maioria, no ramo de prestação de serviços, composto por 13 das empresas respondentes, 09 empresas atuam no ramo industrial e 05 empresas atuam no comércio. A análise foi organizada por meio de Gráficos e Quadros, caracterizando as empresas. 


\section{Análise dos Resultados}

Nesta seção faz-se a validação dos achados da pesquisa a respeito das características organizacionais, no que se refere aos estágios evolutivos da contabilidade gerencial de micro e pequenas empresas do município de Chapecó-SC.

\subsection{Caracterização das empresas}

Observando as 27 empresas da amostra, 13 atuantes na prestação de serviços, 09 no ramo industrial e 05 empresas atuam no comércio. Destas, 13 empresas possuem até 10 funcionários, 07 empresas possuem entre 10 e 20 funcionários e as outras 07 empresas possuem mais de 20 funcionários. Quanto ao faturamento, 06 empresas faturam até 1 milhão, 10 empresas faturam entre 1 e 2 milhões, 06 empresas faturam entre 2 e 3 milhões, 01 empresa entre 3 e 4 milhões e 04 empresas faturam acima de 4 milhões por ano, como podese observar no Gráfico 1 a seguir:

\section{Gráfico 1: Caracterização das empresas da amostra}

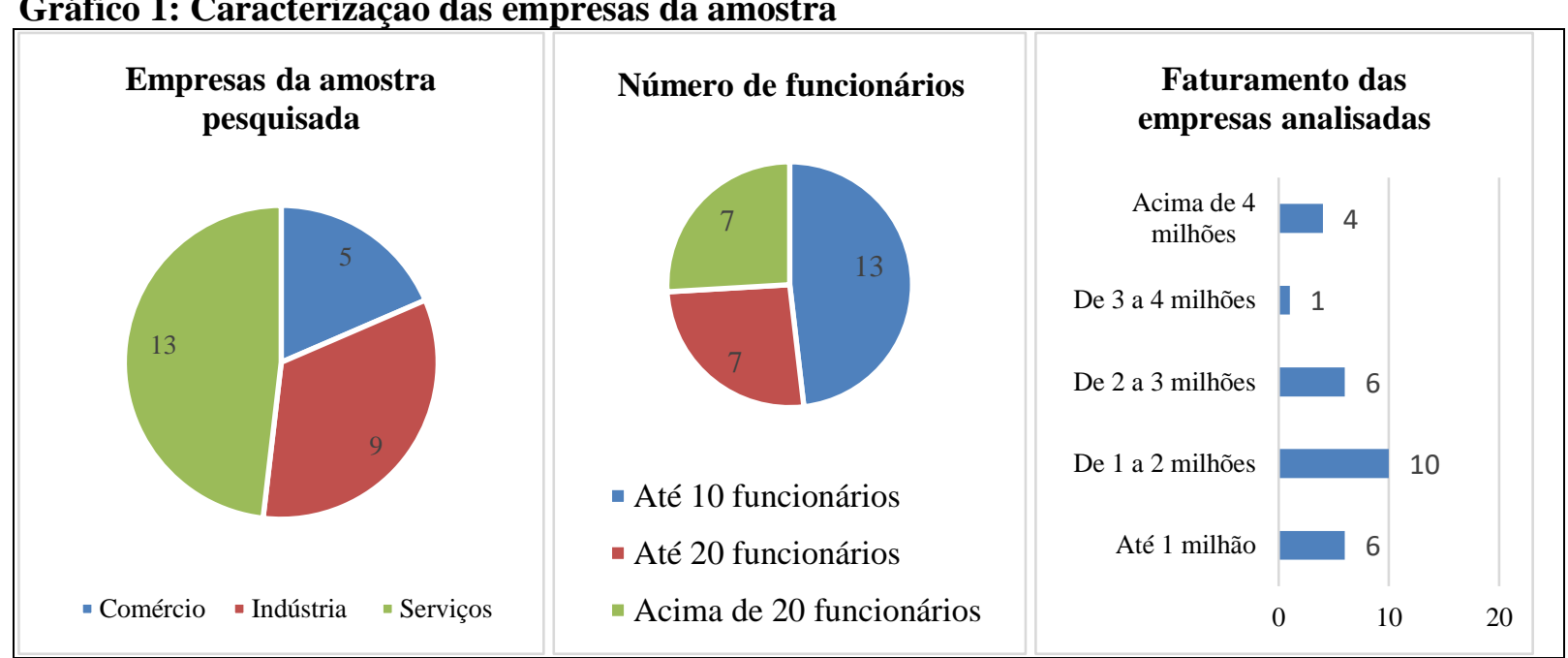

Fonte: Dados da pesquisa.

Com relação a gestão das empresas respondentes, 10 dos gestores são sócios ou donos do negócio, outros 17 respondentes são gestores com funções administrativas, financeiras ou auxiliares, ou seja, são profissionais contratados especificamente para as funções de gestão do negócio em função da sua experiência na área de atuação.

No Quadro 2, a seguir, apresentam-se o detalhamento dos estágios evolutivos da contabilidade gerencial das empresas objeto deste estudo. 
Quadro 2: Caracterização dos estágios das empresas da amostra

\begin{tabular}{|c|c|c|c|c|}
\hline Estágios & Características predominantes dos estágios & 逮 & 厸 & 杬 \\
\hline \multirow{5}{*}{$\begin{array}{l}\text { Estágio 01 - Para a } \\
\text { determinação de } \\
\text { custo e controle } \\
\text { financeiro (CDFC) }\end{array}$} & Utiliza o custo indireto da empresa & \multirow{5}{*}{1} & \multirow{5}{*}{1} & \multirow{5}{*}{3} \\
\hline & Utiliza política orçamentária de controle de custos & & & \\
\hline & Utiliza política orçamentária flexível & & & \\
\hline & Avalia o desempenho baseado em medidas financeiras & & & \\
\hline & $\begin{array}{l}\text { Avalia os grandes investimentos de capital com base no período de } \\
\text { payback e/ou contabilizando a taxa de retorno }\end{array}$ & & & \\
\hline \multirow{12}{*}{ 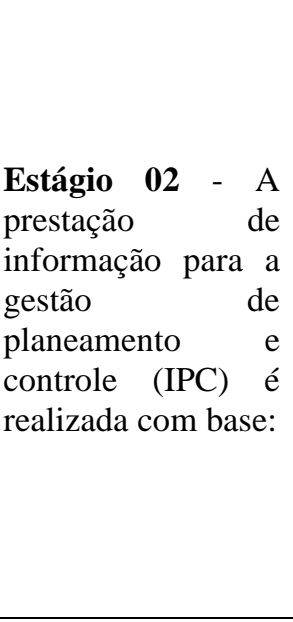 } & $\begin{array}{l}\text { A separação é feita entre custo variável/incremental e custo fixo/não } \\
\text { incremental }\end{array}$ & \multirow{12}{*}{2} & \multirow{12}{*}{3} & \multirow{12}{*}{4} \\
\hline & Utiliza custo indireto por departamentos/setores & & & \\
\hline & Usa regressão e/ou técnicas de curva de aprendizado & & & \\
\hline & Utiliza política orçamentária para o planejamento & & & \\
\hline & Utiliza política orçamentária com a análise de cenários & & & \\
\hline & Utiliza política orçamentária para planejamento estratégico de longo prazo & & & \\
\hline & $\begin{array}{l}\text { Avalia o desempenho baseado em medidas não-financeiras relacionadas a } \\
\text { operações }\end{array}$ & & & \\
\hline & Analisa o custo-volume-lucro para os principais produtos & & & \\
\hline & Analisa a rentabilidade do produto & & & \\
\hline & Utiliza modelos ou métodos de controle de estoque & & & \\
\hline & $\begin{array}{l}\text { Avalia os grandes investimentos de capital com base no método de fluxo } \\
\text { de caixa descontado(s) }\end{array}$ & & & \\
\hline & Utiliza previsão de longo prazo & & & \\
\hline \multirow{7}{*}{$\begin{array}{lr}\text { Estágio } 03 & - \\
\text { redução } & \text { de } \\
\text { desperdícios } & \text { em } \\
\text { recursos } & \\
\text { empresariais } \\
\text { (RWR) é realizada } \\
\text { com base: }\end{array}$} & Atividade baseada em Custos & \multirow{7}{*}{2} & \multirow{7}{*}{4} & \multirow{7}{*}{5} \\
\hline & Atividade baseada em orçamento & & & \\
\hline & Custo de controle da qualidade & & & \\
\hline & Política orçamentária de base zero & & & \\
\hline & $\begin{array}{l}\text { Avaliação de desempenho com base em medidas não-financeiras } \\
\text { relacionadas aos funcionários }\end{array}$ & & & \\
\hline & $\begin{array}{l}\text { Avaliação do risco de grandes investimentos de capital em projetos usando } \\
\text { análise de probabilidade ou simulação por computador }\end{array}$ & & & \\
\hline & $\begin{array}{l}\text { Vulnerabilidade do desempenho da análise de variações hipotéticas ao } \\
\text { avaliar grande investimento de capital }\end{array}$ & & & \\
\hline \multirow{10}{*}{$\begin{array}{lcrr}\text { Estágio } & 04 & - & \text { A } \\
\text { criação } & \text { de } & \text { valor } \\
\text { através } & \text { do } & \text { uso } \\
\text { efetivo } & & \text { dos } \\
\text { recursos } & (\mathrm{CV}) & \text { é } \\
\text { realizada com } & \text { base: }\end{array}$} & Custeio alvo & \multirow{10}{*}{0} & \multirow{10}{*}{1} & \multirow{10}{*}{1} \\
\hline & $\begin{array}{l}\text { Avaliação de desempenho com base em medidas não-financeiras } \\
\text { relacionadas aos clientes }\end{array}$ & & & \\
\hline & $\begin{array}{l}\text { Avaliação de desempenho com base no Lucro ou Valor Econômico } \\
\text { Agregado }\end{array}$ & & & \\
\hline & Benchmarking & & & \\
\hline & Análise de rentabilidade de clientes & & & \\
\hline & $\begin{array}{l}\text { Para a avaliação dos grandes investimentos de capital, aspectos não- } \\
\text { financeiros são documentados e relatados }\end{array}$ & & & \\
\hline & $\begin{array}{l}\text { Cálculo e uso de custo de capital no fluxo de caixa descontado para } \\
\text { avaliação de grandes investimentos de capital }\end{array}$ & & & \\
\hline & Análise de valor para o acionista & & & \\
\hline & Análise da indústria & & & \\
\hline & Análise da posição competitiva & & & \\
\hline
\end{tabular}




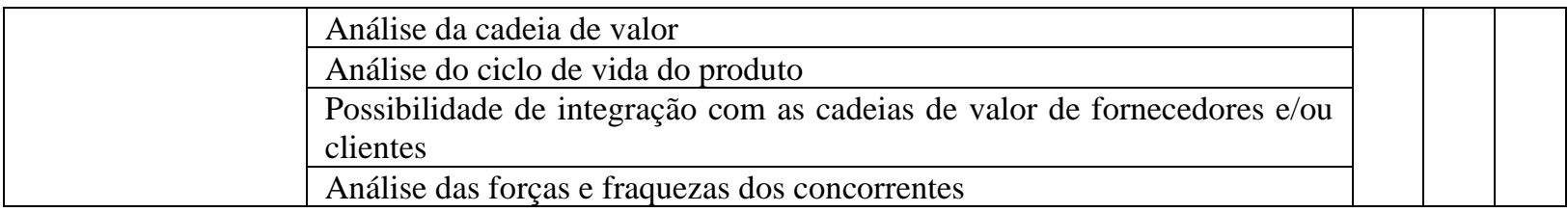

Fonte: Dados da pesquisa.

No Estágio 2 que trata da prestação de informação para a gestão de planejamento e controle (IPC), encontram-se 09 empresas, sendo 2 do comércio, 3 da indústria e 4 prestadoras de serviços, conforme Mattos, Da Costa Freitag e Junior (2010), percebe-se que os gestores se utilizam de práticas que possibilitam um aprimoramento nas informações de controle e planejamento, com base em análises e escolhas, bem como em assessoria interna.

Com relação ao Estágio 3, que trata da redução do desperdício de recursos empresariais (RWR), encontram-se 11 empresas, sendo 2 do comércio, 4 da indústria e 5 prestadoras de serviços. Nota-se que em relação aos estágios pesquisados, foi o que teve o maior número de empresas enquadradas, o que demonstra o uso da tecnologia no setor industrial, sob a ótica de criação de novas técnicas de gerenciamento e produção, ocasionando um melhor controle dos custos (Mattos, Da Costa Freitag \& Junior, 2010).

No que se refere ao Estágio 4, que trata da criação de valor através do uso efetivo dos recursos (CV), encontram-se apenas 02 empresas, sendo 1 da indústria e 1 prestadora de serviços. Percebe-se que das empresas participantes deste estudo, não se utilizam dos recursos de comércio eletrônico com vistas a criação de valor e uso eficaz dos recursos, resta saber se as empresas, ora pesquisadas, estão competindo a nível global ou atuam apenas localmente.

O estudo de Isidoro et al. (2011), as empresas que obtiveram melhores resultados de desempenho foram as que se encontraram no estágio 3. Isso demostra que é comum empresas estarem ainda neste estágio, que tem por finalidade a redução de desperdícios dos recursos que são utilizados nos processos da empresa, através de analises de processos e tecnologia para gerenciar seus custos.

Com relação aos dados, ora apresentados, destaca-se que embora as empresas estejam enquadradas em apenas um único estágio, estes são evolutivos, e não necessariamente há o encerramento de um estágio para que outro venha a se iniciar (Soutes \& De Zen, 2005).

Percebe-se que as empresas participantes deste estudo, em sua maioria, encontram-se centradas na redução de desperdícios ou na prestação de informações para controles internos, a criação de valor por meio do uso efetivo de seus recursos, ainda é pouco explorado pelas empresas, o que denota fragilidade no uso dos recursos via comércio eletrônico, embora a evolução dos estágios representa uma adaptação a novas condições enfrentadas pelas empresas, como a aquisição, correção, melhorias quanto ao uso de tecnologias empregadas anteriormente.

A Figura 2, apresenta o número de empresas enquadradas em cada estágio evolutivo da contabilidade gerencial, de acordo com o seu ramo de atividade.

Como relatado anteriormente, uma empresa do ramo industrial e uma prestadora de serviços foram enquadradas no estágio 4, especificamente, o que difere essas empresas se deve ao fato de, em comparação com empresas em seu segmento de atuação, estarem entre as mais inovadoras. Desde 1996, a indústria participante da pesquisa, foi pioneira na confecção de uniformes na região oeste catarinense, surgiu com o comprometimento de atender com 
qualidade e responsabilidade a demanda do mercado que sentia a necessidade da uniformização.

\section{Gráfico 2: Caracterização dos estágios das empresas}

Estágios das empresas analisadas

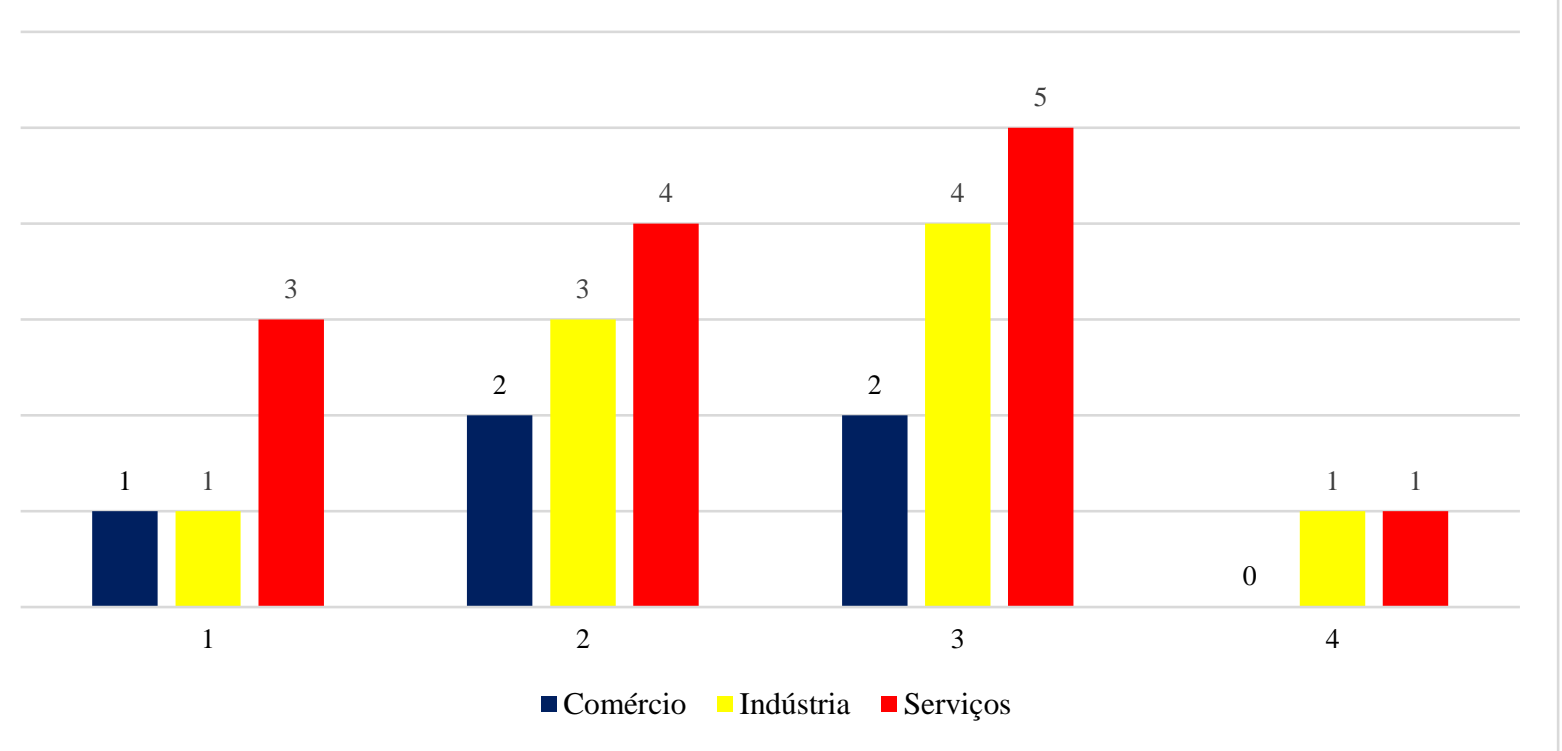

Fonte: Dados da pesquisa.

A participante do estudo, prestadora de serviços, iniciou seus trabalhos em 1989, a partir do processo de transformação econômica-social, onde a educação passou a ter papel relevante, disso percebeu-se a necessidade de ampliação da oferta, aliada à exigência de educação de qualidade e à iniciativa de um grupo de professores, acostumados a desafios, sendo o compromisso social e comunitário sua grande motivação, é considerada uma das melhores escolas de Chapecó, figurando entre as dez melhores notas do ENEM, segundo dados do censo escolar 2018 (INEP, 2018). Atualmente ambas empresas são destaques em suas áreas de atuação, em participação no mercado, percentual de crescimento, reconhecimento e criação de valor perante seus stakeholders.

Os resultados encontrados são respaldados por Abdel-Kader e Luther (2008), observando-se que as empresas com estratégia de baixo custo e alto desempenho estão associadas às técnicas de melhoria dos processos existentes, ao integrar sistemas de gestão, inovação em sistemas de fabricação e técnicas de contabilidade e gestão inovadora com base na sua atividade.

\section{Considerações Finais}

O presente estudo trata das características da estrutura organizacional de micro e pequenas empresas do município de Chapecó-SC. Foram pesquisadas 27 empresas do ramo de indústria, comércio e prestação de serviços, clientes pessoa jurídica de uma instituição financeira de nível nacional com atuação na cidade.

Os achados da pesquisa demonstram que das 27 empresas participantes deste estudo 13 são prestadoras de serviços, 09 indústrias e 05 atuam no comércio. Quanto ao número de 
funcionários das empresas constatou-se que 13 empresas possuem até 10 funcionários, 07 empresas possuem entre 10 e 20 funcionários e 07 empresas possuem mais de 20 funcionários. Com relação ao faturamento, 06 empresas faturam até 1 milhão, 10 empresas faturam entre 1 e 2 milhões, 6 empresas faturam entre 2 e 3 milhões, 1 empresa entre 3 e 4 milhões e 4 empresas faturam acima de 4 milhões por ano. Quanto a gestão dos negócios, para 10 dos respondentes, é feita pelo sócio ou proprietário, os demais afirmam que a gestão é realizada por profissionais contratados.

Quanto aos estágios evolutivos da contabilidade gerencial na estrutura organizacional das empresas, de acordo com o IMAP 1, das 27 empresas pesquisadas, 05 empresas encontram-se no estágio 1, estas apresentam características mais técnicas, baseadas nos controles financeiros e custos. No estágio 2 encontram-se 09 empresas que utilizam na gestão do negócio de planejamento e controle, com base em análises e escolhas e suporte de assessoria interna. Já no estágio 3 foi onde se enquadraram o maior número de empresas, com 11 respondentes, entre as principais características está a redução do desperdício de recursos empresariais, em virtude do uso da tecnologia na melhoria dos seus processos, consequentemente redução dos custos. Apenas 02 empresas se enquadraram no estágio 4, devido principalmente a não utilização do comércio eletrônico, sendo que o estudo não deixou claro se as empresas atuam a nível local ou global.

Como contribuição, o estudo trouxe quais são as características encontradas em predominância nas empresas da amostra. Caracterizou, também, em qual estágio as empresas se encontram, relacionados a essas características predominantes e o que cada estágio traz de predomínios na forma de gerenciar as empresas. Ainda apresentou o ramo de atividade, faturamento e número de colaboradores das empresas e onde elas se encontram dentro dos quatro estágios.

De acordo com Mattos, Da Costa Freitag, \& Junior (2010) e Campos, Marques, \& Neto (2019), há a necessidade de se utilizar dos recursos tecnológicos com viés do cliente, com foco na inovação. $\mathrm{O}$ estudo demonstra a fragilidade das empresas pesquisadas tendo em vista que apenas duas se encontram no estágio 4. Resta saber se as demais empresas estão preocupadas e/ou preparadas para competir em escala global, sendo esta uma proposta para estudos futuros.

Destaca-se a relevância da análise do nível de participação de mercado das empresas com relação ao local de atuação, bem como promover a interação entre empresa, universidade e governo, a fim de elevar o uso de instrumentos e práticas de contabilidade gerencial pelas empresas. Outra sugestão é avançar os estudos a respeito da percepção de valor e uso eficaz dos recursos, até mesmo estendendo este estudo a outras áreas de negócios.

\section{Referências}

Abdel-Kader, M., \& Luther, R. (2008). The impact of firm characteristics on management accounting practices: A UK-based empirical analysis. The British Accounting Review, 40(1), $2-27$.

Anthony, R. N., \& Govindarajan, V. (2008). Sistemas de controle gerencial. AMGH Editora. 
Bazzotti, C., \& Garcia, E. (2006). A importância do sistema de informação gerencial na gestão empresarial para tomada de decisões. Ciências Sociais Aplicadas em Revista, 6(11).

Beuren, I. M., \& Oro, I. M. (2014). Relação entre estratégia de diferenciação e inovação, e sistemas de controle gerencial. Revista de Administração Contemporânea, 18(3), 285-310.

Campos, L. C., Marques, E. V., \& Neto, J. F. C. (2019). Fatores que influenciam a utilização de artefatos de contabilidade gerencial: um estudo nas empresas cearenses. Revista de Administração Unimep, 17(1).

Cezarino, L. O., \& Campomar, M. C. (2006). Micro e pequenas empresas: características estruturais e gerenciais. Revista Hispeci \& Lema, 9, 10-12.

da Costa Ferreira, C., da Silva Macedo, M. Á., de Sant'anna, P. R., Longo, O. C., \& Barone, F. M. (2011). Gestão de capital de giro: contribuição para as micro e pequenas empresas no Brasil. Revista de Administração Pública, 45(3), 863-884.

Dallabona, L. F., Nardelli, L. T., \& Fernandes, A. R. V. (2019). Variáveis Contingenciais e Sistemas de Controle Gerencial Predominantes em uma Rede de Supermercados do Brasil. Revista Evidenciação Contábil \& Finanças, 7(1), 58-77.

de Vicente Bittar, A., Di Serio, L. C., \& de Vasconcellos, M. A. (2018). Micro e Pequenas Empresas Inovadoras: Evidências em Empresas Paulistanas. Revista de Empreendedorismo e Gestão de Pequenas Empresas, 7(3), 85-109.

dos Reis, A. M., \& Teixeira, A. J. C. (2013). Utilización de artefactos de contabilidad gerencial en las sociedades cooperativas agropecuarias de Minas Gerais y su relación con porte y desempeño financiero. Revista de Educação e Pesquisa em Contabilidade, 7(4), 356372.

dos Santos, V., Beuren, I. M., Corrêa, N. L., \& Martins, L. B. B. (2018). Características das empresas e dos gestores que influenciam o uso de controles gerenciais. Advances in Scientific and Applied Accounting, 11(1), 003-023.

Ghilardi, W. J. (2011). Micro ou pequena empresa: na dúvida, não abra!

Gomes, J. S. (1997). Controle gerencial na era da globalização. Contabilidade vista \& revista, 8(2), 26-36.

Grande, J. F., \& Beuren, I. M. (2011). Mudanças de práticas de contabilidade gerencial: aplicação da análise de discurso crítica no relatório da administração de empresa familiar. Revista Base (Administração e Contabilidade) da UNISINOS, 8(2), 133-145. 
Heinzmann, L. M., \& Lavarda, C. E. F. (2011). Cultura organizacional e o processo de planejamento e controle orçamentário. Revista de Contabilidade e Organizações, 5(13), 4-19.

International Federations of Accountants (IFAC). International management accounting practice (IMAP), 1998.

Isidoro, C., Facci, N., Espejo, M. M. D. S. B., Garcias, P. M., \& Moller, C. L. (2011). Estágio evolutivo da contabilidade gerencial nas cooperativas. In: Anais do Congresso Brasileiro de Custos-ABC.

Leone, N. M. C. P. G. (1999). As especificidades das pequenas e médias empresas. Revista de administração, 34(2), 91-94.

Macohon, E. R., \& Beuren, I. M. (2016). Estágios evolutivos da contabilidade gerencial que preponderam em um polo industrial moveleiro. Revista Catarinense da Ciência Contábil, 15(45), 09-22.

Mahamid, I. (2012). Factors affecting contractor's business failure: contractors' perspective. Engineering, Construction and Architectural Management, 19(3), 269-285.

Mattos, M. A., da Costa Freitag, V., \& Junior, P. C. S. (2010). Os Estágios Evolutivos da Contabilidade Gerencial: estudo aplicado às empresas prestadoras de serviços contábeis de Curitiba e região metropolitana. In: Anais do Congresso Brasileiro de Custos-ABC.

Nisiyama, E. K., \& Oyadomari, J. C. T. (2012). Sistemas de controle gerencial e o processo de inovação. Revista de Administração e Inovação, 9(1), 106-125.

Penrose, E. \& Penrose, E. T. (2009). The Theory of the Growth of the Firm. Oxford university press.

Perufo, L. D., \& Godoy, L. P. (2019). Mortalidade de microempresas: Um estudo de campo realizado com microempresários da região centro do estado do Rio Grande do Sul. Revista Pretexto, 20(1), 11-27.

Raupp, F. M., \& Beuren, I. M. (2006). Metodologia da Pesquisa Aplicável às Ciências. Como elaborar trabalhos monográficos em contabilidade: teoria e prática. São Paulo: Atlas.

Silva, G., \& Dacorso, A. L. R. (2013). Inovação aberta como uma vantagem competitiva para a micro e pequena empresa. RAI Revista de Administração e Inovação, 10(3), 251-269.

Soutes, D. O. (2006). Uma investigação do uso de artefatos da contabilidade gerencial por empresas brasileiras. Dissertação (mestrado em Ciências Contábeis) - Universidade de São Paulo, São Paulo. 116 f. 
Soutes, D. O., \& De Zen, M. D. C. (2005). Estágios evolutivos da contabilidade gerencial em empresas brasileiras. In: Congresso USP de Controladoria e Contabilidade.

Teixeira, A. J. C., Gonzaga, R. P., Santos, A. D. V. S. M., \& Nossa, V. (2011). A utilização de ferramentas de contabilidade gerencial nas empresas do Estado do Espírito Santo. Brazilian Business Review, 8(3), 108-127.

Utzig, M. J. S., \& Beuren, I. M. (2014). Relação entre uso interativo do sistema de controle gerencial e diferentes modelos de gestão de inovação. Revista de Administração $e$ Inovação, 11(4), 260-286. 